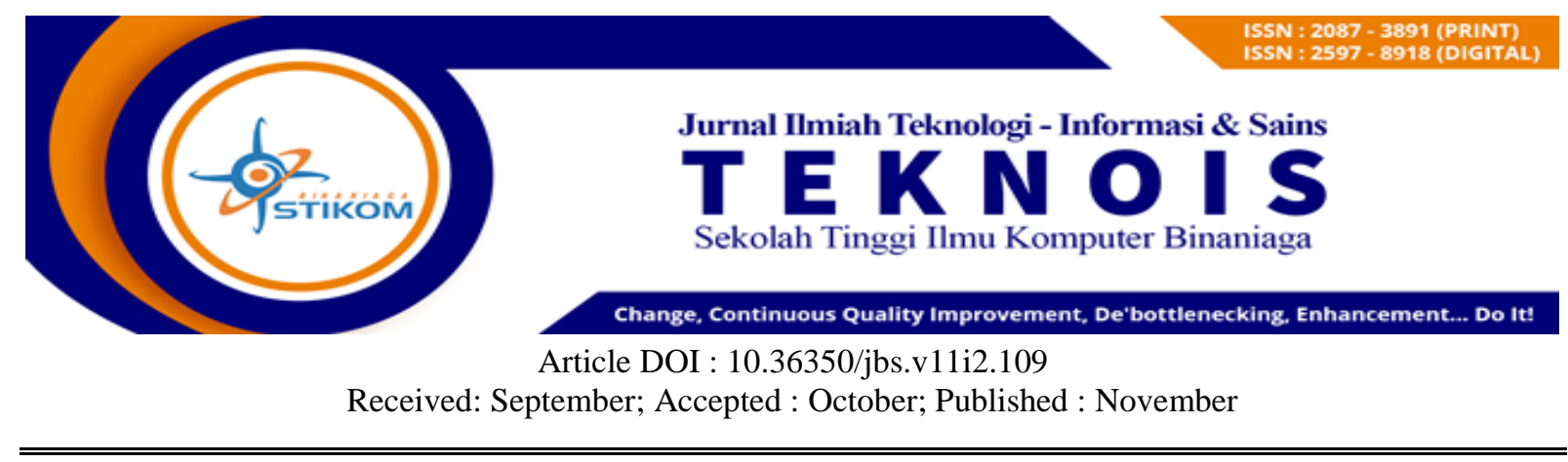

\title{
Penerapan Metode Topsis Untuk Pemilihan Vendor Terbaik
}

\author{
Derman Janner Lubis ${ }^{1^{*}}$, Nur Amalina Anindita ${ }^{2}$ \\ ${ }^{1}$ Sistem Informasi/Universitas Binaniga Indonesia \\ Email: derman_janner@yahoo.com \\ ${ }^{2}$ Sistem Informasi/ Universitas Binaniga Indonesia \\ Email: aninditamalina@gmail.com
}

\begin{abstract}
The selection of vendors to work on a project is an activity that must be carried out effectively and precisely so that the project is carried out in accordance with business needs and does not suffer losses. To get the best vendor ranking, you can use the TOPSIS (Technique for Order Preference by Similarity to Ideal Solution) calculation method. TOPSIS method is a method that generates rankings by calculating the distance between the best solution and the worst solution. The steps to calculate using TOPSIS are identification of alternatives and their values, create a decision matrix, normalize the matrix, calculate the normalization matrix, look for positive and negative solutions, calculate the distance between positive and negative solutions, and calculate relative closeness and sort preferences. In this study using 8 criteria and 5 alternative vendors. Research method using research and development. This method will produce a prototype. The results of the calculation of TOPSIS obtained vendor $c$ who gets the highest score and vendor $b$ with the lowest rank
\end{abstract}

Keywords: vendor; prototype; TOPSIS; alternative; rank.

\section{ABSTRAK}

Pemilihan vendor untuk mengerjakan suatu proyek menjadi kegiatan yang harus dilakukan dengan secara efektif dan tepat agar proyek yang dikerjakan sesuai dengan kebutuhan bisnis dan tidak mengalami kerugian. Untuk mendapatkan peringkat vendor terbaik dapat menggunakan metode perhitungan TOPSIS (Technique for Order Preference by Similarity to Ideal Solution). Metode TOPSIS adalah metode yang menghasilkan peringkat dengan cara menghitung jarak solusi terbaik dan solusi terburuk. Langkah untuk menghitung menggunakan TOPSIS adalah identifikasi alternatif dan nilainya, membuat matriks keputusan, menormalisasikan matriks, menghitung matriks normalisasi, mencari solusi positif dan negatif, menghitung jarak solusi positif dan negatif, menghitung kedekatan relatif dan mengurutkan preferensi. Pada penelitian ini menggunakan 8 kriteria dan 5 alternatif vendor. Teknik penelitian menggunakan research and development yang menghasilkan sebuah prototype. Hasil dari perhitungan topsis didapat vendor $\mathrm{c}$ yang mendapatkan nilai tertingi dan vendor $\mathrm{b}$ dengan peringkat terendah.

Keywords: Vendor; TOPSIS; Prototype; TOPSIS; Alternatif; Ranking..

\section{A. PENDAHULUAN}

\section{Latar Belakang}


Banyaknya aktifitas bisnis yang didukung oleh teknologi, terkadang membutuhkan pihak ketiga untuk membeli jasa atau produk yang menunjang aktifitas bisnis yang ada di industi perbankan. Pemilihan vendor adalah kegiatan untuk menetapkan penyedia barang atau jasa yang akan ditunjuk untuk melaksanakan pekerjaan (Rocky, 2010, p.3). Biasanya, aktifitas bisnis pada bank melibatkan lebih dari satu divisi untuk menunjang proses bisnis yang ada. Maka dari itu, pemilihan pihak ketiga (vendor) harus melibatkan divisi yang terkait dalam sisi proses bisnis maupun kriteria penilaian agar adanya transaparansi penilaian dan kesesuaian proses bisnis yang ada di Bank XXX.

\section{Permasalahan}

Saat ini, pemilihan vendor di Bank XXX masih belum tersentralisasi.Ketidakakuratan, penilaian yang subjektif terhadap vendor tertentu, dan tidak transparansinya kriteria saat penilaian menimbulkan permasalahan dalam pemilihan sebuah vendor.

\section{Tujuan}

Adapun tujuan dari penelitian ini adalah dengan menggunakan metode TOPSIS akan memberikan informasi vendor terbaik dalam proses penilaian vendor dan meminimalisisir kesalahan pemilihan vendor, mengurangi risiko kerugian yang dikarenakan kesalahan pemilihan vendor, terciptanya transparansi kriteria dalam pemilihan vendor.

\section{Tinjauan Pustaka}

a. Metode TOPSIS

"TOPSIS adalah metode pengambilan keputusan multikriteria yang pertama kali diperkenalkan oleh Yoon dan Hwang tahun 1981. Menurut Hwang dan Zeleny." (Kusumadewi, dkk. 2006), TOPSIS didasarkan pada konsep dimana alternatif terpilih yang terbaik tidak hanya memiliki jarak terpendek dari solusi ideal positif, namun juga memiliki jarak terpanjang dari solusi ideal negatif dari sudut pandang geometris dengan menggunakan jarak euclidean untuk menentukan kedekatan relatif dari suatu alternatif dengan solusi optimal.

Dalam penelitian ini menggunakan metode TOPSIS. Adapun langkah-langkahnya adalah:

1) Membangun sebuah matriks keputusan. Matriks keputusan $X$ mengacu terhadap $m$ alternatif yang akan dievaluasi berdasarkan $n$ kriteria. Matriks keputusan X dapat dilihat sebagai berikut.

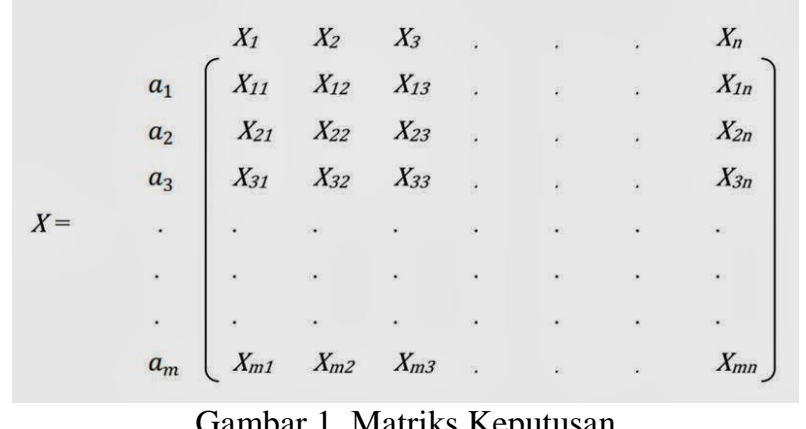

Keterangan: ai $=(i=1,2,3, \ldots, m)$ adalah alternatif-alternatif yang mungkin, $x j=($ $\mathrm{j}=1,2,3, \ldots, \mathrm{n})$ adalah atribut dimana performansi alternatif diukur, xij adalah performansi alternatif ai dengan acuan atribut $x j$.

2) Membuat matriks keputusan yang ternormalisasi. Persamaan yang digunakan untuk mentransformasikan setiap elemen xij.

$$
r_{i j}=\frac{x_{i j}}{\sqrt{\sum_{i=1}^{m} x_{i j}^{2}}}
$$

Gambar 2. Matriks Keputusan Ternormalisasi

3) Membuat matriks keputusan yang ternormalisasi terbobot. 


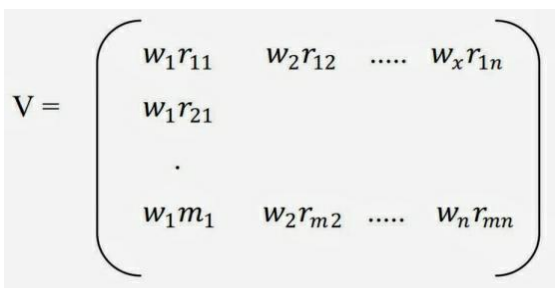

Gambar 3. Matriks Keputusan Ternormalisasi Terbobot

4) Menentukan Matriks solusi ideal positif dan solusi ideal negative. Solusi ideal dinotasikan $\mathrm{A}+$, sedangkan solusi negatif dinotasikan A-.

$$
\begin{aligned}
A^{+} & =\left\{\left(\max v_{i j} \mid j € \mathrm{~J}\right),\left(\min v_{i j} \mid j € \mathrm{~J}^{\prime}\right), i=1,2,3, \ldots . ., \mathrm{m}\right\} \\
& =\left\{v_{1^{+}}, v_{2^{+}}, \ldots . ., v_{n^{+}}\right\} \\
A^{-} & =\left\{\left(\min v_{i j} \mid j € \mathrm{~J}\right),\left(\max v_{i j} \mid j € \mathrm{~J}^{\prime \prime}\right), i=1,2,3, \ldots . ., \mathrm{m}\right\} \\
& =\left\{v_{1}, v_{2}, \ldots . ., v_{n^{-}}\right\}
\end{aligned}
$$

Gambar 4. Matriks Solusi Ideal Positif dan Negatif

5) Menghitung separasi, $\mathrm{Si}+$ ialah jarak alternatif dari solusi ideal.

$$
\begin{aligned}
A^{+} & =\left\{\left(\max v_{i j} \mid j € \mathrm{~J}\right),\left(\min v_{i j} \mid j € \mathrm{~J}^{\prime}\right), i=1,2,3, \ldots . ., \mathrm{m}\right\} \\
& =\left\{v_{1^{+}}, v_{2^{+}}, \ldots . ., v_{n^{+}}\right\} \\
A^{-} & =\left\{\left(\min v_{i j} \mid j € \mathrm{~J}\right),\left(\max v_{i j} \mid j € \mathrm{~J}^{\prime}\right), i=1,2,3, \ldots . ., \mathrm{m}\right\} \\
& =\left\{v_{1}, v_{2}, \ldots . ., v_{n^{-}}\right\}
\end{aligned}
$$

Gambar 5. Matriks Solusi Ideal Positif

6) Menghitung Kedekatan terhadap solusi ideal positif.

$$
C_{i}^{+}=\frac{S_{i^{-}}}{S_{i^{+}}+S_{i^{-}}} \text {, dengan } 0<C_{i}^{+}<1 \text { dan } i=1,2,3, \ldots, m
$$

Gambar 6. Solusi Ideal Positif

\section{B. METODE}

Objek Penelitian yang akan penyusun telliti adalah informasi tentang proses pemilihan vendor di Bank XXX. Dalam penelitian ini, penyusun mengumpulkan data-data yang berhubungan dengan proses pemilihan vendor di Bank XXX, seperti alur pengadaan proyek, penilaian proyek yang dimenangkan oleh vendor dan peringkat vendor pada proyek core banking migration. Metode penelitian dan pengembangan (research and development) digunakan untuk menguji efektifitas sebuah produk. Jika sebuah produk sudah ada, maka pengembangan produk ditujukan agar produk tersebut agar menjadi lebih praktis dan efisien.Langkah-langkah penelitian dan pengembangan meliputi perancangan, produksi dan evaluasi. Pada tahap perancangan, kegiatan yang dilakukan adalah membuat rencana pembuatan sebuah produk. Pada tahap produksi, kegiatan yang dilakukan adalah pembuatan sebuah produk sesuai dengan rencana yang telah dibuat. Tahap evaluasi, kegiatan menguji dan menilai produk dalam kesesuaian spesifikasi yang telah ditentukan. Metode yang digunakan untuk menyelesaikan masalah penilaian pemilihan vendor ini adalah metode TOPSIS. Perhitungan TOPSIS, dibuat dalam sebuah prototype agar bisa diuji dan validasinya dalam menyelesaikan masalah. Menurut Pressman (2010:43) menyatakan bahwa pendekatan metode prototype adalah metode yang cocok untuk membuat sebuah aplikasi. Pada pembuatan prototype ini membantu untuk mengidentifikasi fitur dan algoritma yang akan ada di aplikasi yang akan dibuat. Tahapan untuk menggunakan metode prototype tedapat lima tahapan yang diiliustrasikan pada Gambar 7 .

Prosedur pengembangan pada penelitian ini adalah:

1. Pengumpulan Data

Pada tahap ini, mengobservasi masalah yang ada dengan mencari data dan pemberian kuisioner dan melakukan wawancara. 
2. Identifikasi Masalah

Pada tahap ini, kegiatan yang dilakukan adalah melakukan observasi tentang masalah yang ada dan identifikasi semua kebutuhan yang pada pembuatan prototype.

3. Penentuan Metode TOPSIS

Pada tahap ini, kegiatan yang dilakukan adalah melakukan penentuan metode perangkingan pemilihan vendor terbaik dengan metode TOPSIS dengan membuat matriks keputusan ternormalisasi, membuat matriks keputusan ternormalisasi terbobot, menentukan matriks solusi negatif dan positif, menghitung jarak antara solusi negatif dan positif, mengurutkan preferensi,dan setelah itu mendapatkan hasil vendor terbaik.

4. Analisis Dan Perancangan Prototype

Pada tahap ini, merencanakan desain prototype yang akan dibuat dan membuat prototype sesuai dengan rencana dan desain yang sudah dibuat.

5. Pengujian Prototype

Pada tahap ini, aktifitas yang dilakukan adalah menguji prototype dengan pengujian blackbox, PSSUQ dan spearman rank.

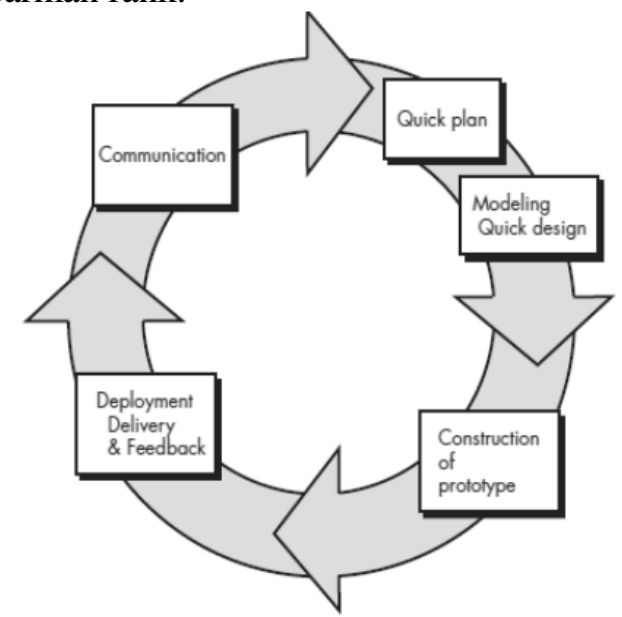

Gambar 7 Model Prototype (Sumber: Pressman, 2010)

\section{HASIL DAN PEMBAHASAN}

\section{Hasil}

\section{a. Identifikasi Kebutuhan Aplikasi}

Pada pengembangan aplikasi pemilihan vendor ini memiliki fungsi mencari vendor terbaik dengan menggunakan perhitungan pada metode TOPSIS yang nantinya aplikasi ini memberikan informasi urutan vendor dari yang tertinggi ke terendah beserta skor yang diperoleh di setiap vendor. Aplikasi pemilihan vendor terbaik akan mempunyai 2 user, yaitu admin beeding dan super admin beeding dan mempunyai tampilan untuk input nilai per kriteria pada proyek yang akan dikerjakan oleh beberapa vendor yang dilakukan oleh admin beeding. Super admin beeding akan mengelola parameter proyek yang akan dikerjakan vendor dan bobot di setiap kriteria Proses bisnis akan dikembangkan dengan menggunakan metode TOPSIS digambarkan pada gambar 8.

\section{b. Pengumpulan Data}

Pada tahapan pengumpulan data ini, data data yang dibutuhkan antara lain data vendor, data kriteria dan bobot, data penilaian untuk setiap vendor per kriteria.

1) Data Vendor

Data vendor ini adalah data vendor yang mengikuti proyek Core banking migration bank XXX Customer pada bulan Maret 2019. Bank XXX adalah sebuah ilustrasi dari sebuah perusahaan bank swasta. Data vendor pada proyek ini yaitu:

Table 3 Data Vendor

\begin{tabular}{|c|c|}
\hline No & Nama Vendor \\
\hline 1 & Vendor A \\
\hline 2 & Vendor B \\
\hline
\end{tabular}


Volume 11 Number 2 November 2021 Page. 19-30

Journal Homepage : http://teknois.stikombinaniaga.ac.id/index.php/JBS

DOI Link : http://doi.org/10.36350/jbs.v11i2

\begin{tabular}{|c|c|}
\hline 3 & Vendor C \\
\hline 4 & Vendor D \\
\hline 5 & Vendor E \\
\hline
\end{tabular}

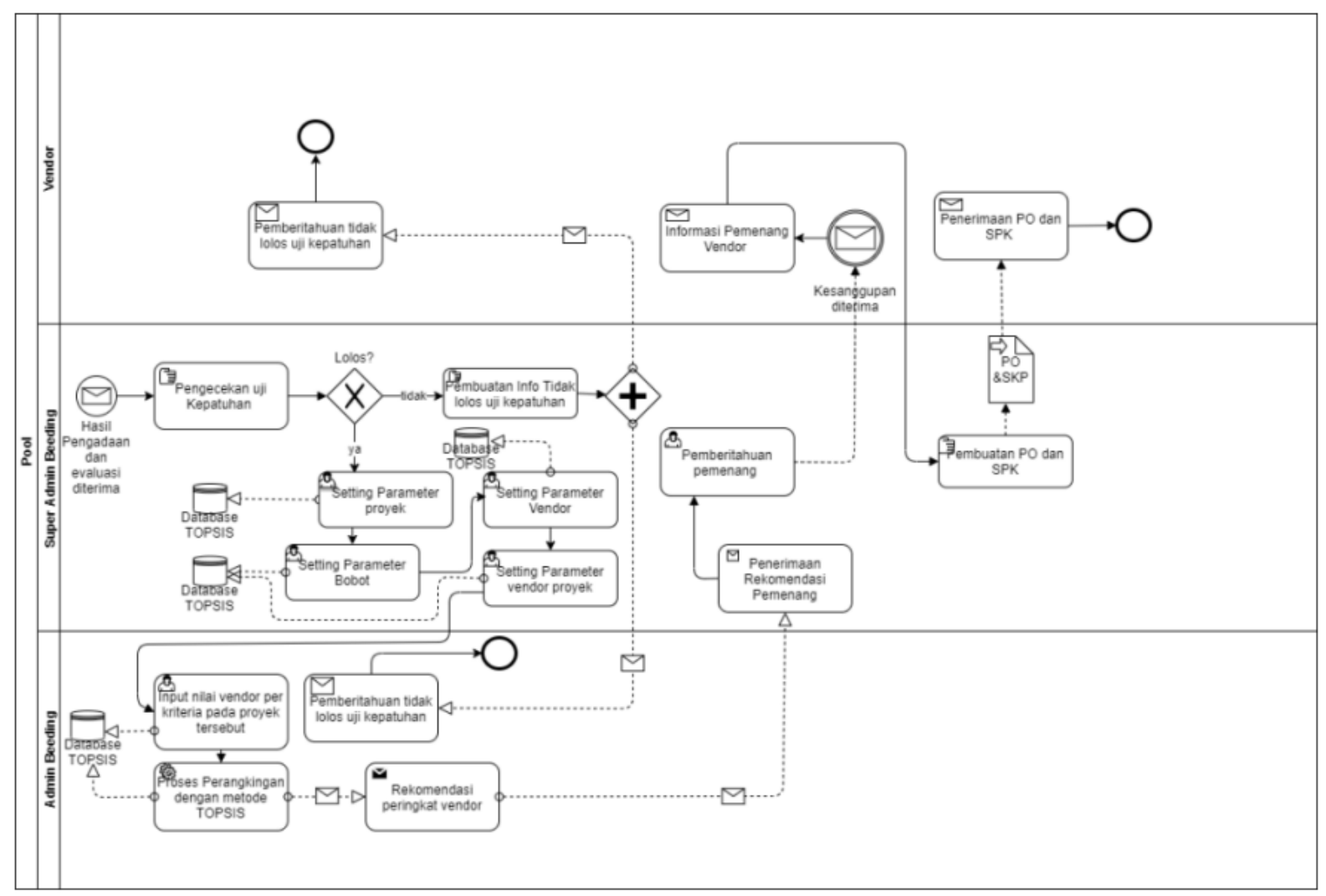

Gambar 8 Proses Bisnis Setelah Menggunakan TOPSIS

2) Data Kriteria dan Bobot

Pada penelitian ini menggunakan kriteria dan bobot yang dideskripsikan pada tabel 4 .

Table 4 Data Kriteria, Bobot dan Tipe

\begin{tabular}{|c|l|c|l|}
\hline No & \multicolumn{1}{|c|}{ Kriteria } & Bobot & \multicolumn{1}{c|}{ Jenis } \\
\hline 1 & Deliverable time and Document & 0.3397 & Keuntungan \\
\hline 2 & Price & 1.6085 & Biaya \\
\hline 3 & Ease of Implementation & 1.1085 & Keuntungan \\
\hline 4 & Capability Business Process & 0.7751 & Keuntungan \\
\hline 5 & Guaranty & 0.5251 & Keuntungan \\
\hline 6 & Training & 0.3251 & Biaya \\
\hline 7 & Portofolio Experience on Indonesia's Banking Industry & 0.1585 & Keuntungan \\
\hline 8 & Security and Lisence & 0.125 & Biaya \\
\hline
\end{tabular}

3) Data Penilaian

Data penilaian vendor pada proyek core banking migration bank XXX di deskripsikan pada tabel 5

Tabel 5 Data Penilaian Vendor Proyek Core Banking Migration Bank XXXX

\begin{tabular}{|l|l|l|l|l|l|l|l|l|}
\hline Alternatif & $\left(\boldsymbol{c}_{1}\right)$ & $\left(\boldsymbol{c}_{2}\right)$ & $\left(\boldsymbol{c}_{\mathbf{3}}\right)$ & $\left(\boldsymbol{c}_{\mathbf{4}}\right)$ & $\left(\boldsymbol{c}_{5}\right)$ & $\left(\boldsymbol{c}_{6}\right)$ & $\left(\boldsymbol{c}_{7}\right)$ & $\left(\boldsymbol{c}_{8}\right)$ \\
\hline Vendor $1\left(A_{1}\right)$ & 4 & 4 & 1 & 3 & 2 & 2 & 2 & 3 \\
\hline Vendor $2\left(_{2}\right)$ & 3 & 4 & 1 & 2 & 2 & 1 & 2 & 3 \\
\hline Vendor $3\left(A_{3}\right)$ & 4 & 1 & 3 & 3 & 2 & 2 & 3 & 3 \\
\hline Vendor $4\left(A_{4}\right)$ & 4 & 1 & 4 & 4 & 3 & 3 & 4 & 4 \\
\hline Vendor $5\left(A_{5}\right)$ & 3 & 4 & 1 & 3 & 2 & 3 & 2 & 3 \\
\hline
\end{tabular}


Volume 11 Number 2 November 2021 Page. 19-30

Journal Homepage : http://teknois.stikombinaniaga.ac.id/index.php/JBS

DOI Link : http://doi.org/10.36350/jbs.v11i2

Pada penilaian vendor ini mempunyai bobot preferensi sebagai berikut:

Table 6 Bobot Preferensi

\begin{tabular}{|l|l|}
\hline Bobot & Nilai \\
\hline Kurang Baik & 1 \\
\hline Cukup & 2 \\
\hline Baik & 3 \\
\hline Sangat Baik & 4 \\
\hline
\end{tabular}

\section{c. Analisa dengan Metode TOPSIS}

1) Membuat Matriks Keputusan

$$
x_{i j}=\left[\begin{array}{llllllll}
4 & 4 & 1 & 3 & 2 & 2 & 2 & 3 \\
3 & 4 & 1 & 2 & 2 & 1 & 2 & 3 \\
4 & 1 & 3 & 3 & 2 & 2 & 3 & 3 \\
4 & 1 & 4 & 4 & 3 & 3 & 4 & 4 \\
3 & 4 & 1 & 3 & 2 & 3 & 2 & 3
\end{array}\right]
$$

2) Menghitung matriks ternormalisasi

Perhitungan $C_{1}$

$$
\begin{aligned}
& r_{11=\frac{4}{\sqrt{4^{2}+3^{2}+4^{2}+4^{2}+3^{2}}}}=0,4924 \\
& r_{21}=\frac{3}{\sqrt{4^{2}+3^{2}+4^{2}+4^{2}+3^{2}}}=0,3693 \\
& r_{31}=\frac{4}{\sqrt{4^{2}+3^{2}+4^{2}+4^{2}+3^{2}}}=0,4924 \\
& r_{41}=\frac{4}{\sqrt{4^{2}+3^{2}+4^{2}+4^{2}+3^{2}}}=0,4924 \\
& r_{51}=\frac{3}{\sqrt{4^{2}+3^{2}+4^{2}+4^{2}+3^{2}}}=0,3693
\end{aligned}
$$

Perhitungan $C_{2}$

$$
\begin{aligned}
& r_{12}=\frac{4}{\sqrt{4^{2}+4^{2}+1^{2}+1^{2}+4^{2}}}=0,5657 \\
& r_{22}=\frac{4}{\sqrt{4^{2}+4^{2}+1^{2}+1^{2}+4^{2}}}=0,5657 \\
& r_{32}=\frac{1}{\sqrt{4^{2}+4^{2}+1^{2}+1^{2}+4^{2}}}=0,1414 \\
& r_{42}=\frac{1}{\sqrt{4^{2}+4^{2}+1^{2}+1^{2}+4^{2}}}=0,1414 \\
& r_{52}=\frac{4}{\sqrt{4^{2}+4^{2}+1^{2}+1^{2}+4^{2}}}=0,5657
\end{aligned}
$$

Langkah perhitungan ini juga dilakukan untuk perhitungan $C_{3}$, Perhitungan $C_{4}$, Perhitungan $C_{5}$, Perhitungan $C_{6}$, Perhitungan $C_{7}$, Perhitungan $C_{8}$

3) Menghitung matriks Normalisasi Terbobot

$$
\begin{aligned}
& v_{11}=0.3397 \times 0.4924=0.1672 \\
& v_{21}=0.3397 \times 0.3693=0.1254 \\
& v_{31}=0.3397 \times 0.4924=0.1672 \\
& v_{41}=0.3397 \times 0.4924=0.1673 \\
& v_{51}=0.3397 \times 0.3693=0.1254 \\
& v_{12}=1.6085 \times 0.5657=0.9098 \\
& v_{22}=1.6085 \times 0.5657=0.9098 \\
& v_{32}=1.6085 \times 0.1414=0.2274
\end{aligned}
$$


Volume 11 Number 2 November 2021 Page. 19-30 Journal Homepage : http://teknois.stikombinaniaga.ac.id/index.php/JBS DOI Link : http://doi.org/10.36350/jbs.v11i2

$$
\begin{aligned}
& v_{42}=1.6085 \times 0.1414=0.2274 \\
& v_{52}=1.6085 \times 0.5657=0.9098 \\
& v_{13}=1.1085 \times 0.1890=0.2094 \\
& v_{23}=1.1085 \times 0.1890=0.2094 \\
& v_{33}=1.1085 \times 0.5669=0.6284 \\
& v_{43}=1.1085 \times 0.7559=0.8379 \\
& v_{53}=1.1085 \times 0.1890=0.2094
\end{aligned}
$$

Maka didapatkan matriks ternomalisasi terbobot sebagai berikut :

$\left[\begin{array}{rrrrrrrr}0.1672 & 0.9098 & 0.2094 & 0.3392 & 0.2100 & 0.1251 & 0.0521 & 0.05200 \\ 0.1254 & 0.9098 & 0.2094 & 0.2261 & 0.2100 & 0.0625 & 0.0521 & 0.05200 \\ 0.1672 & 0.2274 & 0.6284 & 0.3392 & 0.2100 & 0.1251 & 0.0781 & 0.05200 \\ 0.1672 & 0.2274 & 0.8379 & 0.4522 & 0.3150 & 0.1877 & 0.1042 & 0.0693 \\ 0.1254 & 0.9098 & 0.2094 & 0.3392 & 0.2100 & 0.1877 & 0.0198 & 0.0520\end{array}\right]$

4) Mencari solusi ideal positif $A^{+}$dan solusi negatif $A^{-}$

$$
\begin{aligned}
& A_{1}^{+}=\max \{0.1672 ; 0.1254 ; 0.1672 ; 0.1672 ; 0,1254\}=0.1672 \\
& A_{2}^{+}=\min \{0.9098 ; 0.9098 ; 0.2274 ; 0.2274 ; 0,9098\}=0.2274 \\
& A_{3}^{+}=\max \{0.2094 ; 0.2094 ; 0.6284 ; 0.8379 ; 0,2094\}=0.8379 \\
& A_{4}^{+}=\max \{0.3392 ; 0.2261 ; 0.3392 ; 0.4522 ; 0,3392\}=0.4522 \\
& A_{5}^{+}=\max \{0.2100 ; 0.2100 ; 0.2100 ; 0.3150 ; 0,2100\}=0.3150 \\
& A_{6}^{+}=\min \{0.1251 ; 0.0625 ; 0.1251 ; 0.1877 ; 0,1877\}=0.0625 \\
& A_{7}^{+}=\max \{0.0521 ; 0.0521 ; 0.0781 ; 0.1042 ; 0,0198\}=0.1042 \\
& A_{8}^{+}=\min \{0.0520 ; 0.0520 ; 0.0520 ; 0.0693 ; 0,0520\}=0.0520 \\
& v^{+}=\{0.1672 ; 0.2274 ; 0.8379 ; 0.4522,0.3150 ; 0.0625 ; 0.1042 ; 0.0520\} \\
& A_{1}^{-}=\min \{0.1672 ; 0.1254 ; 0.1672 ; 0.1672 ; 0,1254\}=0.1254 \\
& A_{2}^{-}=\max \{0.9098 ; 0.9098 ; 0.2274 ; 0.2274 ; 0,9098\}=0.9098 \\
& A_{3}^{-}=\min \{0.2094 ; 0.2094 ; 0.6284 ; 0.8379 ; 0,2094\}=0.2094 \\
& A_{4}^{-}=\min \{0.3392 ; 0.2261 ; 0.3392 ; 0.4522 ; 0,3392\}=0.2261 \\
& A_{5}^{-}=\min \{0.2100 ; 0.2100 ; 0.2100 ; 0.3150 ; 0,2100\}=0.2100 \\
& A_{6}^{-}=\max \{0.1251 ; 0.0625 ; 0.1251 ; 0.1877 ; 0,1877\}=0.1877 \\
& A_{7}^{-}=\min \{0.0521 ; 0.0521 ; 0.0781 ; 0.1042 ; 0,0198\}=0.0198 \\
& A_{R}^{-}=\max \{0.0520 ; 0.0520 ; 0.0520 ; 0.0693 ; 0,0520\}=0.0693 \\
& v^{-}=\{0.1254 ; 0.9098 ; 0.2094 ; 0.2261,0.2100 ; 0.1877 ; 0.0198 ; 0.0693\}
\end{aligned}
$$

5) Mencari jarak dengan solusi ideal positif $s_{1}^{+}$dan jarak solusi negatif $s_{i}^{-}$

$$
\begin{aligned}
& s_{1}^{\dagger}=\sqrt{(0.1672-0.1672)^{2}+(0.9098-0.2274)^{2}}+(0.2094-0.8379)^{2}+(0.3392-0.4522)^{2} \\
& +(0.2100-0.3150)^{2}+(0.1251-0.0625)^{2}+(0.0521-0.1042)^{2} \\
& +(0.0520-0.0520)^{2}=0.9439 \\
& s_{2}^{\dagger}=\sqrt{(0.1254-0.1672)^{2}+(0.9098-0.2274)^{2}}+(0.2094-0.8379)^{2}+(0.2261-0.4522)^{2} \\
& +(0.2100-0.3150)^{2}+(0.0625-0.0625)^{2}+(0.0521-0.1042)^{2} \\
& +(0.0520-0.0520)^{2}=0.9629 \\
& s_{3}^{\dagger}=\sqrt{(0.1672-0.1672)^{2}+(0.2274-0.2274)^{2}}+(0.6284-0.8379)^{2}+(0.3392-0.4522)^{2} \\
& +(0.2100-0.3150)^{2}+(0.1251-0.0625)^{2}+(0.0781-0.1042)^{2} \\
& +(0.0520-0.0520)^{2}=0.2688
\end{aligned}
$$

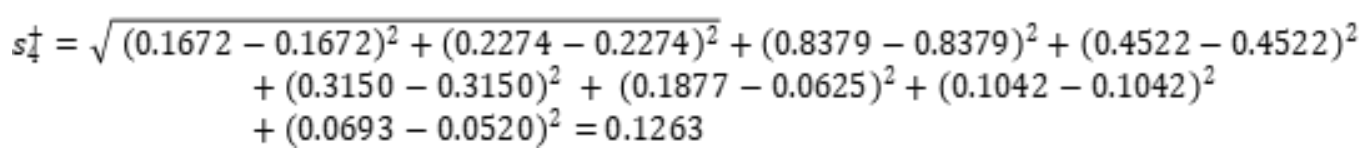


Volume 11 Number 2 November 2021 Page. 19-30 Journal Homepage : $\underline{\text { http://teknois.stikombinaniaga.ac.id/index.php/JBS }}$ DOI Link : http://doi.org/10.36350/jbs.v11i2

$$
\begin{aligned}
& s_{5}^{\ddagger}=\sqrt{(0.1254-0.1672)^{2}+(0.9098-0.2274)^{2}}+(0.2094-0.8379)^{2}+(0.3392-0.4522)^{2} \\
& +(0.2100-0.3150)^{2}+(0.1877-0.0625)^{2}+(0.0198-0.1042)^{2} \\
& +(0.0520-0.0520)^{2}=0.9534 \\
& s_{1}^{-}=\sqrt{(0.1672-0.1254)^{2}+(0.9098-0.9098)^{2}}+(0.2094-0.2094)^{2}+(0.3392-0.2261)^{2} \\
& +(0.2100-0.2100)^{2}+(0.1251-0.1877)^{2}+(0.0521-0.0198)^{2} \\
& +(0.0520-0.0693)^{2}=0.1406
\end{aligned}
$$

$$
\begin{aligned}
& s_{2}^{-}=\sqrt{(0.1254-0.1245)^{2}+(0.9098-0.9098)^{2}}+(0.2094-0.2094)^{2}+(0.2261-0.2261)^{2} \\
& +(0.2100-0.2100)^{2}+(0.0625-0.1877)^{2}+(0.0521-0.0198)^{2} \\
& +(0.0520-0.0693)^{2}=0.1304 \\
& s_{3}^{-}=\sqrt{(0.1672-0.1254)^{2}+(0.2274-0.9098)^{2}}+(0.6284-0.2094)^{2}+(0.3392-0.2261)^{2} \\
& +(0.2100-0.2100)^{2}+(0.1251-0.1877)^{2}+(0.0781-0.0198)^{2} \\
& +(0.0520-0.0693)^{2}=0.8144 \\
& s_{4}^{-}=\sqrt{(0.1672-0.1254)^{2}+(0.2274-0.9098)^{2}}+(0.8379-0.2094)^{2}+(0.4522-0.2261)^{2} \\
& +(0.3150-0.2100)^{2}+(0.1877-0.1877)^{2}+(0.1042-0.0198)^{2} \\
& +(0.0693-0.0693)^{2}=0.9652 \\
& s_{5}=\sqrt{(0.1254-0.1254)^{2}+(0.9098-0.9098)^{2}}+(0.2094-0.2094)+(0.3392-0.2261)^{2} \\
& +(0.2100-0.2100)^{2}+(0.1877-0.1877)^{2}+(0.0198-0.0198)^{2} \\
& +(0.0520-0.0693)^{2}=0.1143
\end{aligned}
$$

6) Menghitung Kedekatan relatif $c_{i}^{+}$

$$
\begin{aligned}
& c_{1}^{+}=\frac{0.1406}{0.9439+0.1406}=0.1297 \\
& c_{2}^{+}=\frac{0.1304}{0.9629+0.1304}=0.1192 \\
& c_{3}^{+}=\frac{0.8144}{0.2688+0.8144}=0.7518 \\
& c_{4}^{+}=\frac{0.9652}{0.1263+0.9652}=0.8842 \\
& c_{5}^{+}=\frac{0.1143}{0.9534+0.1143}=0.1071
\end{aligned}
$$

7) Mengurutkan Preferensi sesuai dengan dari tertinggi ke terendah.

Maka hasil peringkat vendor terbaik adalah di deskripsikan pada tabel

Table 7 Peringkat Vendor Terbaik

\begin{tabular}{|l|l|l|}
\hline Alternatif & Hasil & Peringkat \\
\hline Vendor D & 0.88426 & 1 \\
\hline Vendor C & 0.75181 & 2 \\
\hline Vendor A & 0.1297 & 3 \\
\hline Vendor B & 0.11927 & 4 \\
\hline Vendor E & 0.10712 & 5 \\
\hline
\end{tabular}

\section{d. Desain Aplikasi}

1) Protoype Aplikasi

Hasil dari penelitian ini juga menghasilkan sebuah prototype aplikasi yang dapat menginputkan penilaian terhadap semua peserta vendor pada sebuah proyek. Pada prototype ini terdapat 4 tampilan yaitu tampilan daftar proyek, daftar kriteria, informasi peringkat vendor, dan pengisian nilai per kriteria. Prototipe untuk tampilan daftar proyek digambarkan pada gambar berikut : 
Volume 11 Number 2 November 2021 Page. 19-30 Journal Homepage : http://teknois.stikombinaniaga.ac.id/index.php/JBS DOI Link : http://doi.org/10.36350/jbs.v11i2

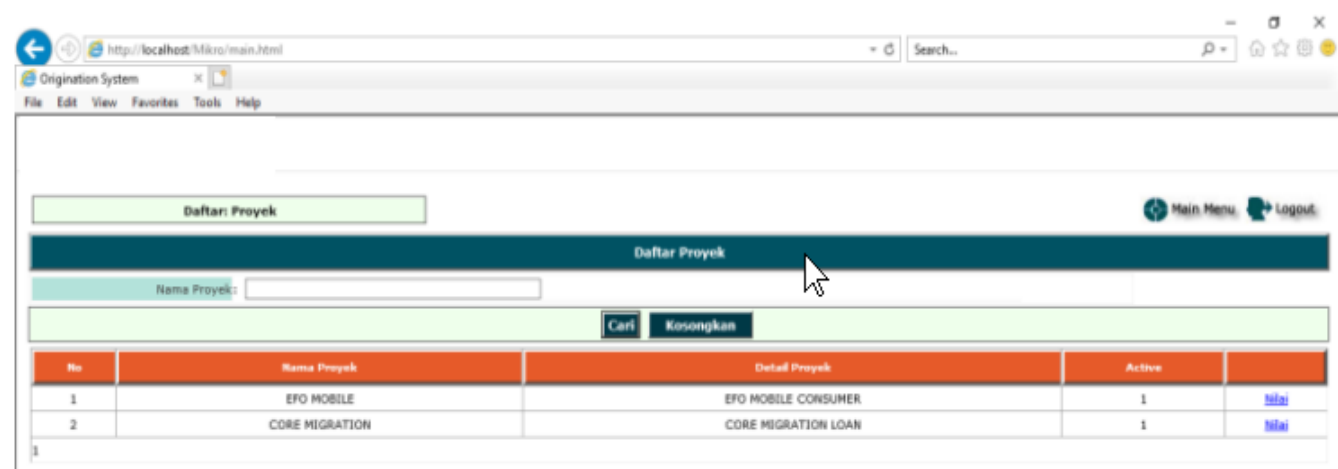

Gambar 9 Tampilan Daftar Proyek

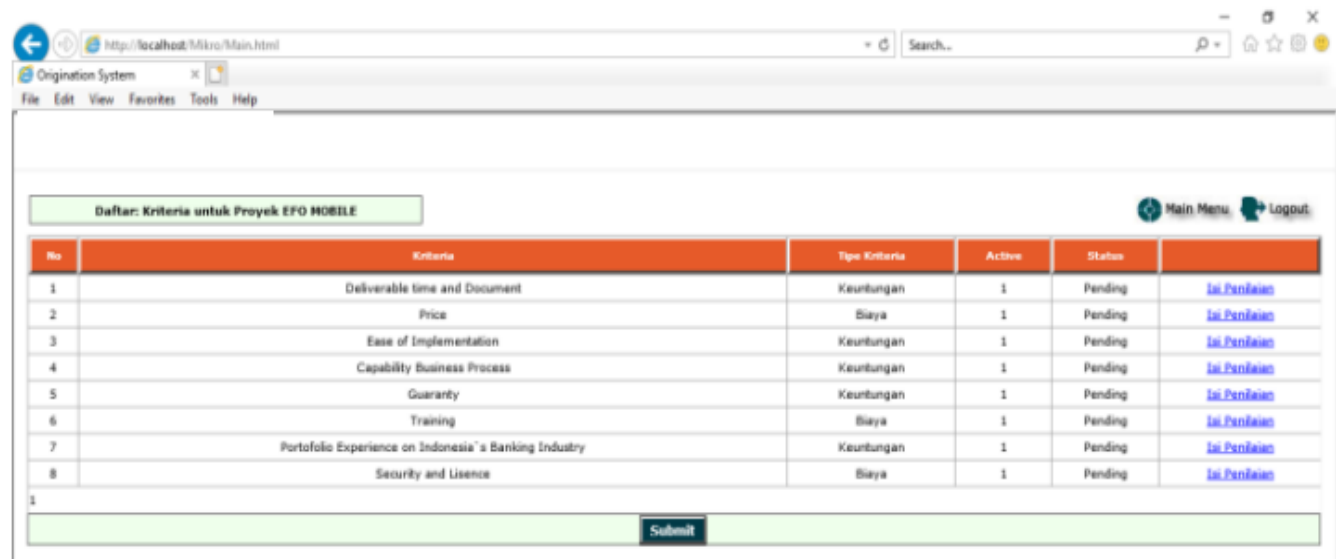

Gambar 10 Tampilan Datar Kriteria

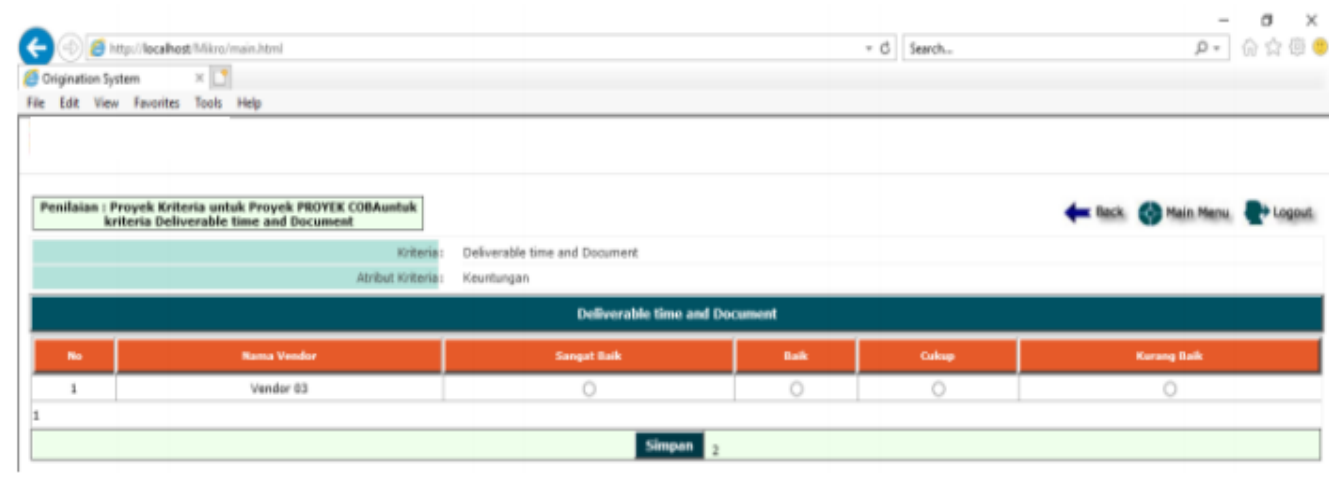

Gambar 11 Pengisian nilai vendor per kriteria

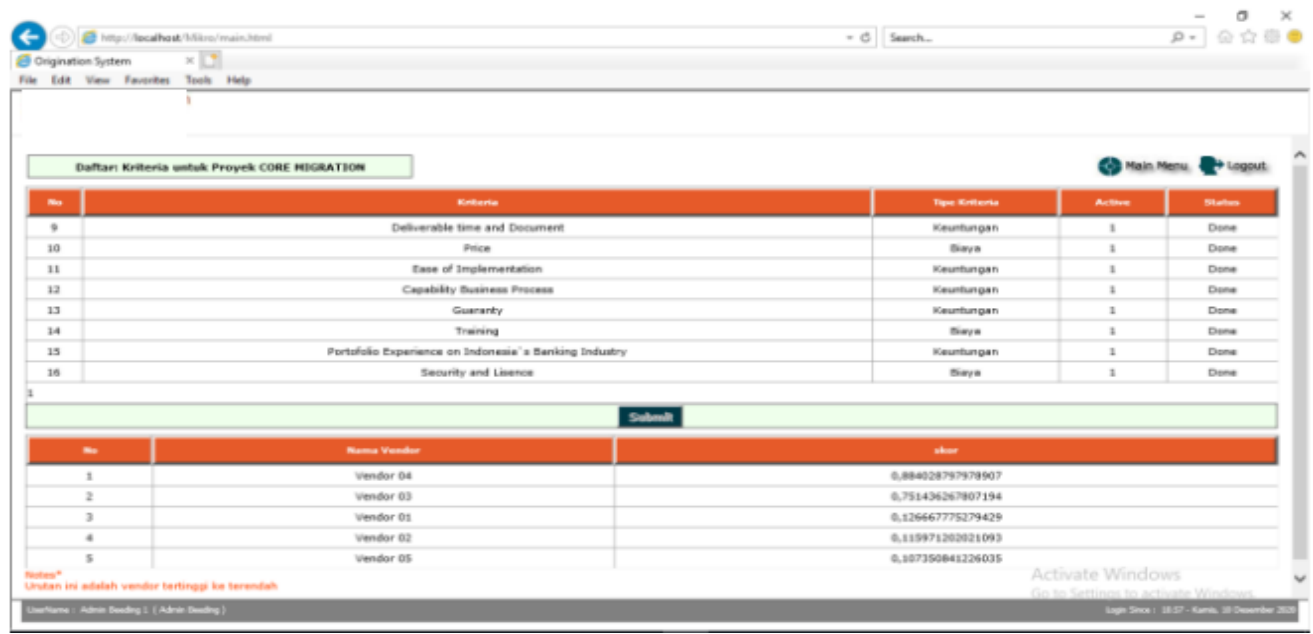

Gambar 12 Informasi Peringkat Vendor 


\section{Pembahasan}

a. Hasil Analisa Perhitungan TOPSIS

Data data yang sudah dikumpulkan dan dihitung dengan metode TOPSIS, maka hasil peringkat dari vendor pada proyek core banking migration dapat di deskripsikan pada tabel dibawah ini.

Table 8 Peringkat Vendor Setelah Menggunakan TOPSIS

\begin{tabular}{|c|c|c|}
\hline Alternatif & Hasil & Peringkat \\
\hline Vendor A & 0.88426 & 1 \\
\hline Vendor B & 0.75181 & 2 \\
\hline Vendor C & 0.1297 & 3 \\
\hline Vendor D & 0.11927 & 4 \\
\hline Vendor E & 0.10712 & 5 \\
\hline
\end{tabular}

b. Uji Hasil

Uji hasil pada penelitian pengembangan ini adalah perbandingan hasil antara sebelum menggunakan metode TOPSIS dengan hasil setelah menggunakan metode TOPSIS. Perbandingan hasil ini menggunakan korelasi spearman rank. Tabel perhitungan korelasi spearman rank dideskripsikan pada tabel 9

Table 9 Perhitungan Korelasi Spearman Rank

\begin{tabular}{|c|c|c|c|c|}
\hline \multirow[b]{2}{*}{ Alternatif } & \multirow{2}{*}{$x$} & \multirow{2}{*}{$y$} & $d$ & $(d)^{2}$ \\
\hline & & & $x-y$ & $(x-y)^{2}$ \\
\hline Vendor C & 1 & 2 & -1 & 1 \\
\hline Vendor A & 2 & 3 & -1 & 1 \\
\hline Vendor D & 3 & 1 & 2 & 4 \\
\hline Vendor E & 4 & 5 & -1 & 1 \\
\hline Vendor B & 5 & 4 & 1 & 1 \\
\hline Jumlah & & & $\sum d^{2}$ & 8 \\
\hline
\end{tabular}

Keterangan:

$x=$ Peringkat sebelum penerapan metode

$y=$ Peringkat setelah penerapan metode

Selanjutnya dihitung dengan menggunakan korelasi spearman rank yaitu:

$\rho=1-\frac{6 \sum d_{i}^{2}}{n\left(n^{2}-1\right)}$

$\rho=1-\frac{6(8)}{5\left(5^{2}-1\right)}$

$\rho=1-\frac{48}{120}$

$\rho=1-0,35$

$\rho=0,65$

Bedasarkan nilai $\rho$ yang diperoleh dari hasil perhitungan korelasi spearman rank dengan nilai 0.6, maka nilai tersebut termasuk kedalam kategori tinggi yang memiliki makna bahwa terjadi perubahan peringkat vendor terbaik antara sebelum dan sesudah menggunakan metode TOPSIS.

\section{KESIMPULAN}

\section{Kesimpulan}

Bedasarkan tujuan penelitian yang dilakukan, maka disimpulkan:

a. Dengan menggunakan metode TOPSIS, dapat mengefisiensikan pemilihan vendor terbaik sehingga lebih mudah untuk mencari vendor terbaik. 
Volume 11 Number 2 November 2021 Page. 19-30

Journal Homepage : http://teknois.stikombinaniaga.ac.id/index.php/JBS

DOI Link : http://doi.org/10.36350/jbs.v11i2

b. Penentuan hasil peringkat dengan menggunakan metode TOPSIS dapat membantu perusahaan dalam memberikan ketepatan dalam penentuan vendor terbaik pada sebuah proyek.

\section{Saran}

Saran yang dapat diberikan dari hasil penelitian ini adalah:

a. Pemilihan vendor pada penelitian ini menggunakan 8 kriteria, maka dapat menambahkan kriteria seperti kriteria inovasi dan teknologi yang dipakai untuk mengerjakan projek.

b. Metode yang digunakan pada pemilihan vendor ini adalah metode topsis, maka dapat ditambhakan seperti metode ANP untuk menentukan bobot.

\section{E. DAFTAR PUSTAKA}

[1] Ak Suswinarno. 2012. Aman dari Risiko dalam Pengadaan Barang/Jasa Pemerintah. Visimedia. Jakarta

[2] Arikunto Suharsimi. 2009. Manajemen Penelitian. Rineka Cipta. Jakarta

[3] Aryanto Yuri, Budi Harijanto, Tan watequlis S. 2018. Virtualisasi Komputer dalam Pembelajaran Jaringan.Polinema Press. Malang

[4] Ascarya and Diana Yumanita. 2005. Pusat Pendidikan dan Studi Kebanksentraan Bank Indonesia. Jakarta

[5] Astuti Miguna dan Agni Rizkita Amanda. 2020. Pengantar Manajemen Pemasaran. Deepublish. Yogyakarta

[6] A.S Rosa dan M. Shalahudin. 2015. Rekayasa Perangkat Lunak Terstruktur dan Berorientasi Objek. Bandung. Informatika

[7] Balagurasamy, E. 2008. Programming in c\#. 2nd ed. Tata McGrawHill. New Delhi

[8] Enterprise, Jubille. 2016. Pengenalan HTML dan CSS. ELEX MEDIA KOMPUTINDO. Jakarta

[9] Malhorta, Jyoti J and Bhavana S Tiple. 2008. Software Testing and Quality. Assurance. Nirali Prakashan. Mumbai

[10] Marbun, Rocky. 2010. Tanya Jawab Seputar Tata Cara Pengadaan Barang/Jasa Pemerintah. Transmedia Pustaka. Jakarta

[11] Maturidi, Ade Djohar .2014. Metode Penelitian Teknik Informatika.Deepublish. Yogyakarta

[12] Pressman, Roger S. 2010. Software Engineering A Pratitioner's Approach 7th.McGraw Hill Higher Education. NewYork

[13] Putera Andika Persada. 2019. Hukum Perbankan: Analisis Mengenai Prinsip, Produk Risiko dan Manajemen Risiko dalam Perbankan. Scopindo Media Pustaka. Surabaya

[14] Sobari Ade. 2020. Administrasi Database SQL Server 2019 For Student \& Developers. Lentera Ilmu Cendekia. Jakarta

[15] Soemohadiwidjojo, Arini T.2014. Mudah Menyususn SOP. Penebar Plus. Jakarta

[16] Sugiyono. 2013. Metode Penelitian Pendidikan Pendekatan Kuantitatif, Kualitatif, dan R\&D. Alfabeta. Bandung

[17] Sugiyono. 2019. Metode Penelitian \& Pengembangan Research and Development. Alfabeta. Bandung

[18] Simamora Bilson. 2005. Analisis Multivariant Pemasaran. Gramedia Pustaka Utama. Jakarta

[19] Utami Ema, Sukrisno. 2005. 10 Langkah Belajar Logika dan Algoritma Menggunakan Bahasa C dan C++ di GNU/Linux. Andi. Yogyakarta 
Volume 11 Number 2 November 2021 Page. 19-30

Journal Homepage : http://teknois.stikombinaniaga.ac.id/index.php/JBS

DOI Link : http://doi.org/10.36350/jbs.v11i2

[20] Utojo Hertin Indira. 2019. Manajemen Pengadaan Barang dan Jasa.

[21] Wanto anjar and Limbong Tonni, dkk. 2020. Sistem Pendukung Keputtusan Metode \& Implementasi. Yayasan Kita Menulis 